\title{
Microestrutura de uma Solda Dissimilar entre o Aço Inoxidável Ferrítico AISI $410 S$ e 0 Aço Inoxidável Austenítico AISI 304L Soldado pelo Processo FSW
}

\author{
Tathiane Caminha Andrade ${ }^{1}$, Cleiton Carvalho Silva ${ }^{1}$, Hélio Cordeiro de Miranda ${ }^{1}$, Marcelo Ferreira Motta ${ }^{1}$, \\ Jesualdo Pereira Farias'1, Luciano Andrei Bergman², Jorge Fernandes dos Santos² \\ 1 Laboratório de Engenharia de Soldagem, Departamento de Engenharia Metalúrgica e de Materiais, Universidade Federal do \\ Ceará - UFC,, Campus do Pici, Fortaleza, CE, Brasil. \\ 2 Solid State Joining Processes, Institute of Materials Research, Helmholtz-Zentrum Geesthacht, Geesthacht, Germany.
}

Recebido: 04 Set., 2015

Aceito: 18 Dez., 2015

E-mail: cleiton@metalmat.ufc.br (CCS)
Resumo: O presente trabalho visa investigar a microestrutura formada na soldagem dissimilar entre chapas de aços inoxidáveis ferríticos AISI 410S e aços inoxidáveis austeníticos AISI 304L pelo processo friction stir welding. A soldagem foi realizada com o ajuste dos seguintes parâmetros: rotação $450 \mathrm{rpm}$; velocidade de soldagem de 1,0 mm/s; e força axial 40 kN. O aço AISI 410S foi posicionado no lado de avanço enquanto que o aço AISI 304L foi posicionado no lado de retrocesso. A análise consistiu de preparação metalográfica e caracterização microestrutural por microscopia ótica e microscopia eletrônica de varredura. Para o aço AISI 410 foi observada a formação de martensita associada com ferrita na zona de mistura (ZM), zona termomecanicamente afetada (ZTMA) e na zona afetada pelo calor (ZAC). As características do processo de soldagem FSW resultaram num refino de grão para o aço inoxidável ferrítico, posicionado no lado de avanço, tanto na ZM quanto nas ZTMA e ZAC. O mesmo comportamento não foi observado para o lado austenítico.

Palavras-chave: Soldagem dissimilar; Friction stir welding; Aço inoxidável; Refino de grão.

\section{Microstructure of AISI 410S Ferritic Stainless Steel and AISI 304L Austenitic Stainless Steel Dissimilar Weld Joined by FSW Process}

\begin{abstract}
This study aims to investigate the microstructure formed in dissimilar welding between AISI 410S ferritic stainless steel and AISI 304L austenitic stainless steels plates by friction stir welding process. The welding was performed setting the following parameters: rotation $450 \mathrm{rpm}$; welding speed of $1.0 \mathrm{~mm} / \mathrm{s}$; and axial force $40 \mathrm{kN}$. The AISI 410S was positioned on the advancing side while the AISI $304 \mathrm{~L}$ steel was positioned in the retracting side. The analysis consisted of metallographic preparation and microstructural characterization by optical microscopy and scanning electron microscopy. For AISI 4105 ferritic stainless steel was found martensite formation in association with ferrite in the stir zone (SZ), thermomechanically affected zone (TMAZ) and heat-affected zone (HAZ). The characteristics of the FSW welding process for the ferritic stainless steel resulted in grain refining, whether in the SZ, TMAZ and HAZ. In the austenitic stainless steel side, the same behavior was not found.
\end{abstract}

Key-words: Dissimilar welding; Friction stir welding; Stainless steel; Grain refining.

\section{Introdução}

Quando comparados aos aços inoxidáveis austeníticos, os aços inoxidáveis ferríticos fornecem aproximadamente a mesma resistência à corrosão, porém possuem mais baixa ductilidade, tenacidade e soldabilidade [1]. Podem ser usados em uma grande variedade de aplicações quando a resistência à corrosão por pites e/ou resistência à corrosão sob-tensão é mais requerida do que resistência mecânica [2]. Outra grande vantagem dos aços inoxidáveis ferríticos é a ausência de níquel em sua composição, visto que o níquel é um dos elementos de liga mais caros, o que eleva consideravelmente os custos dos aços inoxidáveis austeníticos em comparação com os aços ferríticos, sendo esta uma grande motivação para a substituição total ou parcial de aços inoxidáveis austeníticos por ferríticos, desde que sejam atendidos critérios de propriedades mecânicas e resistência à corrosão. Comparativamente, algumas vantagens dos aços inoxidáveis ferríticos em relação aos austeníticos que podem ser destacadas são, por exemplo, sua baixa expansão térmica; excelente resistência à oxidação em alta temperatura sendo menos susceptíveis à descamação que os austeníticos; alta condutividade térmica, ou seja, conduzem o calor de forma mais uniforme que os austeníticos; quando estabilizados ao nióbio, apresentam Este é um artigo publicado em acesso aberto (Open Access)
sob a licença Creative Commons Attribution Non-Commercia que permite uso, distribuição e reprodução em qualquer trabalho original seja corretamente citado. 
excelente resistência à fluência; são significativamente menos susceptíveis à recuperação elástica durante a conformação a frio; apresentam um maior limite de escoamento (similar aos aços carbonos comuns) que os austeníticos tipo 304; e são menos suscetíveis à corrosão por pites e à corrosão sob-tensão [3,4].

Todos estes fatores têm atraído a atenção de inúmeros setores industriais como, por exemplo, indústria automotiva, indústrias ferroviária e metroviária, petróleo e gás, sucroalcooleira, petroquímico, indústria naval, farmacêutico, alimentos, bebidas, eletrodomésticos, utensílios de cozinha, construção civil e arquitetura, dentre outros. As potencialidades desta classe de materiais, especialmente no Brasil, são as mais interessantes, inclusive em relação à redução de custo e aumento de competitividade proporcionada pela escolha adequada dos aços inoxidáveis ferríticos em substituição aos austeníticos, dependendo da aplicação e das exigências em termos de resistência à corrosão.

Contudo, a expansão das aplicações dos aços inoxidáveis ferríticos é limitada por problemas metalúrgicos decorrentes da soldagem destes aços, especialmente o intenso crescimento de grão [5]. Em geral, recomenda-se que essas ligas sejam soldadas com um baixo aporte térmico e altas velocidades de soldagem para manter a zona de crescimento de grãos o mais estreita possível [6,7]. Técnicas avançadas de soldagem como feixe de elétrons e laser, as quais são caracterizadas por um curto tempo de interação com alta densidade de energia também têm sido investigadas [8-10]. Outras técnicas como pulsação de corrente e adição de agentes nucleantes na tentativa de refinar os grãos da zona fundida em processos autógenos têm sido tentadas, mas sem alcançar o sucesso esperado [11,12].

No início da década de 1990 foi desenvolvido no TWI (Inglaterra) um novo processo de soldagem por friç̧ão denominado friction stir welding (FSW) [13], o qual tem sido considerado o mais significativo desenvolvimento em união de metais das últimas décadas, sendo um tema de grande interesse científico e com forte aplicação industrial [14].

O processo FSW tem como princípio básico a união de materiais no estado sólido com o uso de uma ferramenta não-consumível que rotaciona inserida entre as bordas das chapas a serem unidas, descrevendo a trajetória ao longo da junta a ser soldada [15]. O aquecimento é resultado do atrito da ferramenta enquanto o escoamento de material para a coalescência entre as partes a serem unidas é devido a um severo processo de deformação plástica [16].

Dentre as vantagens reportadas para este processo, pode ser destacada sua vocação para a produção de solda com baixa tendência de crescimento de grãos, devido às menores temperaturas alcançadas se comparado à processos de fusão, bem como por fenômenos associados à conformação plástica [17].

Embora existam trabalhos na literatura sobre a soldagem de aços inoxidáveis pelo processo FSW, uma grande lacuna científica tem sido identificada na literatura, a qual corresponde à soldagem dissimilar entre aços inoxidáveis ferríticos e aços inoxidáveis austeníticos pelo processo FSW. Considerando a importância destas ligas para o setor industrial e a existência de vários fenômenos de transformação e degradação de suas propriedades, especialmente em decorrência das etapas de processamento destes materiais, torna-se de fundamental importância o desenvolvimento de estudos que possibilitem não só a aplicabilidade do processo à união com sucesso destes materiais mas também possibilitem a identificação e a compreensão dos fenômenos ocorridos durante a soldagem, contribuindo de forma decisiva para o avanço científico e tecnológico. O presente trabalho visa contribuir um pouco com este tema, investigando a microestrutura formada na soldagem dissimilar pelo processo Friction Stir Welding de chapas de aços inoxidáveis ferríticos e austeníticos.

\section{Metodologia}

Para a realização do presente estudo foram utilizadas chapas dos aços inoxidáveis AISI 410S (ferrítico) e AISI 304L (austenítico) com 4,0 mm de espessura. A composição química das respectivas ligas é apresentada na Tabela 1. Foi utilizado argônio puro como gás de purga para minimizar oxidação superficial.

Tabela 1. Composição química do metal de adição e do metal de base (\% em peso).

\begin{tabular}{ccccccccccc}
\hline \multirow{2}{*}{ Item } & \multicolumn{8}{c}{ Composição química (\% em peso) } \\
& $\mathbf{C}$ & $\mathbf{C r}$ & $\mathbf{N i}$ & $\mathbf{M o}$ & $\mathbf{M n}$ & $\mathbf{S i}$ & $\mathbf{N b}$ & $\mathbf{T i}$ & $\mathbf{N}$ & $\mathbf{F e}$ \\
Aço 410S & 0,014 & 11,5 & 0,17 & - & 0,45 & 0,39 & - & 0,10 & - & Bal. \\
Aço 304L & 0,023 & 17,7 & 6,6 & 0,17 & 1,69 & 0,53 & 0,03 & - & 0,10 & Bal. \\
\hline
\end{tabular}


Microestrutura de uma Solda Dissimilar entre o Aço Inoxidável Ferrítico AISI 410 e o Aço Inoxidável Austenítico AISI 304L Soldado pelo Processo FSW

A soldagem dissimilar das chapas em configuração de topo foi realizada utilizando o HZG Gantry System, do Helmholtz-Zentrum Geesthacht (Alemanha), o qual é apresentado na Figura 1. O equipamento permite um controle preciso dos parâmetros durante a execução da solda, tais como as forças, o torque aplicado pela ferramenta e a velocidade de rotação e translação da ferramenta. Os seguintes parâmetros selecionados foram rotação $450 \mathrm{rpm}$, velocidade de soldagem de 1,0 mm/s, e força axial $40 \mathrm{kN}$. Foi usada uma ferramenta de nitreto de boro cúbico policristalino (PCBN) com pino de 9,2 de diâmetro, 3,75 mm de comprimento e um ombro de 36,8 mm. A chapa de aço inoxidável ferrítico AISI 410 S foi posicionada no lado de avanço da ferramenta, enquanto a chapa de aço inoxidável austenítico AISI 304L foi mantida no lado de retrocesso (Figura 2). Esta configuração foi adotada com base em estudos preliminares envolvendo a seleção dos parâmetros de soldagem [18].

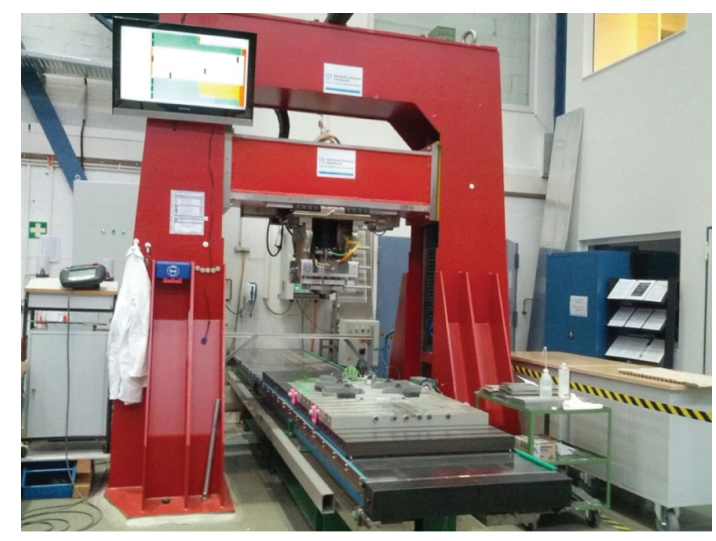

Figura 1. Sistema pórtico HZG utilizado na soldagem das chapas de aço inoxidável pelo processo friction stir welding (FSW).

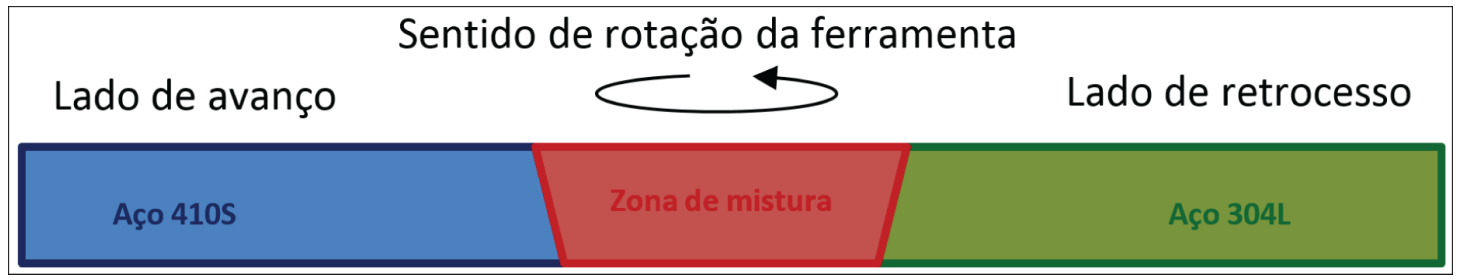

Figura 2. Configuração da junta de topo dissimilar na qual o aço inoxidável ferrítico foi posicionado no lado de avanço da ferramenta e o aço inoxidável austenítico foi posicionado no lado de retrocesso.

A avaliação microestrutural consistiu de preparação metalográfica convencional, por meio de lixamento até a granulometria de 600 mesh e polimento com pasta de diamante até $1 / 4$ de micron, seguido de ataque químico. Para a revelação da microestrutura de ambas as ligas foram utilizados diferentes reagentes químicos. A estrutura austenítica foi atacada com ácido oxálico $10 \%$ em peso e o aço inoxidável ferrítico foi atacado com reagente Vilella.

As análises microestruturais foram realizadas no Laboratório de Engenharia de Soldagem da UFC e na Central Analítica da UFC. Para a avaliação inicial foi utilizado um microscópio ótico Carl Zeiss Axio Observer Z1 com Sistema de aquisição de imagens integrado. Análises de microscopia eletrônica de varredura foram realizadas na Central Analítica da UFC. Utilizou-se um microscópio FEI Quanta FEG 450, com sistema de microanálise de EDS Oxford e sistema de análise de EBSD Oxford acoplados.

\section{Resultados}

A primeira etapa das análises das juntas soldadas consistiu na inspeção visual do acabamento superficial das soldas. Esta etapa permite a identificação de defeitos macroscópicos como trincas, cavidades, poros e rebarbas nas bordas. Além disso, também foi avaliada a geometria da solda bem como a penetração. 
Os resultados mostraram que a junta apresentou bom acabamento superficial. O furo de saída da ferramenta também foi examinado e não foram observadas quaisquer evidencias de trincas ou defeitos. A Figura 3 mostra trechos representativos da superfície da junta dissimilar apresentado bom acabamento superficial em termos de zona de mistura com mínima formação de rebarbas ao longo das bordas da zona de mistura. O formado da zona de mistura seguiu a geometria aproximada da ferramenta FSW. Também foi confirmada por análise macro e microestrutural da seção transversal a ausência de defeitos internos e um preenchimento completo da zona de mistura.

Força: 40 kN; Rotação: 450 rpm
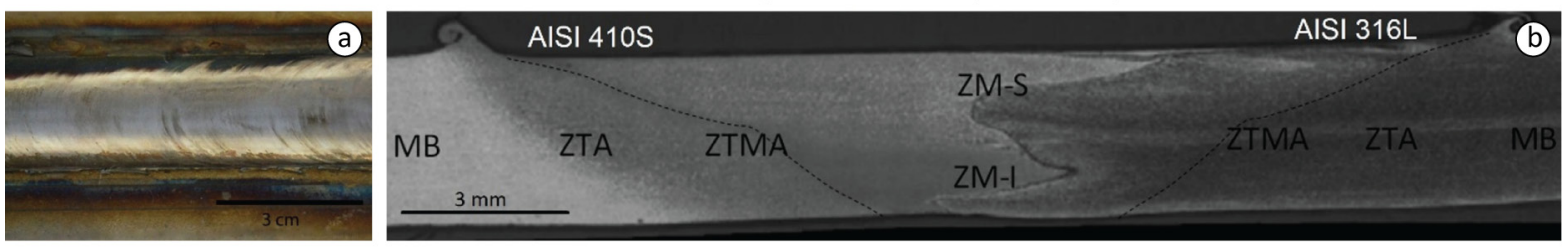

Figura 3. Acabamento superficial da solda (a) e seção transversal da junta; (b) MB - Metal base; ZAC - zona afetada pelo calor; ZTMA - Zona termomecanicamente afetada; ZM-S - Zona de mistura superior; ZM-I - Zona de mistura inferior.

A microestrutura da junta soldada foi investigada por diversas técnicas. De uma forma geral a literatura indica a existência de quatro zonas principais a saber: zona de mistura (ZM) - consiste na zona que experimenta intensa deformação plástica e aquecimento com subsequente recristalização dinâmica total ou parcial dependendo do material; zona termomecanicamente afetada (ZTMA) - que corresponde à zona que sofreu os efeitos tanto da deformação plástica quanto do aquecimento; zona termicamente afetada (ZTA) - zona que experimentou somente efeito do aquecimento; e metal de base (MB) - o qual não foi afetado nem por calor nem por deformação [19]. Além destas zonas, como a soldagem consiste na união de duas ligas diferentes, existe ainda outra zona de interesse que não está contemplada na nomenclatura descrita anteriormente e corresponde à região da interface. Análises especificas da microquímica e cristalografia da interface serão publicadas posteriormente.

A macrografia da seção transversal da solda dissimilar AISI 410S/AISI 304L obtida por microscopia ótica indicando as diferentes regiões da junta soldada apresentada na Figura 3, serve de base para indicar as posições de onde foram adquiridas as imagens de micrografia. É possível observar as diferenças em termos de material, estando o aço AISI 410S à esquerda e o aço AISI 316L à direita, conforme Figura 3b. Além das zonas reportadas anteriormente (ZM; ZTMA e ZAC), foram observadas diferenças em termos de microestrutura e tamanho de grão na ZTMA e, principalmente, na ZM entre a porção superior e inferior do aço ferrítico. Na ZM deste aço foi observado um gradiente de granulometria. Por isso, foram denominadas as zonas de mistura superior (ZM-S) e inferior (ZM-I), as quais foram influenciadas térmica e mecanicamente pelo ombro e pelo pino da ferramenta, respectivamente.

Para o lado do aço inoxidável ferrítico (410S) foram observadas alterações significativas de microestrutura, especialmente na ZM, sendo estabelecidas duas regiões. A primeira região localizada na parte superior da chapa até próximo da meia espessura (ZM-S) foi caracterizada por grãos equiaxiais de ferrita (claros) aproximadamente igual ao metal de base, circundados por grãos menores de martensita (escuros), como pode ser observado nas Figuras 4a e 4b. Foi utilizada microscopia eletrônica de varredura para confirmar a presença de ambas as fases. Na Figura 5 é apresentado o resultado da análise de MEV operando no modo SE da microestrutura da zona de mistura com alta magnificação, na qual é possível identificar inequivocamente a presença de martensita (M) juntamente com grãos de ferrita (F).

No caso da ZM-S, houve uma aparente manutenção do tamanho de grão ferrítico, visto que o fenômeno de crescimento dos grãos ferríticos comumente observado na soldagem por fusão destes aços [2], foi suprimido pela menor temperatura de pico alcançada durante a soldagem com FSW. Além disso, a transformação parcial da ferrita em austenita em alta temperatura, cuja nucleação ocorre ao longo dos contornos de grão da ferrita é outro fator limitante para o crescimento dos grãos, resultando num tamanho de grão da ferrita aproximadamente igual aos grãos equiaxiais ferríticos observados no metal de base. Esta austenita formada no aquecimento, se transforma 

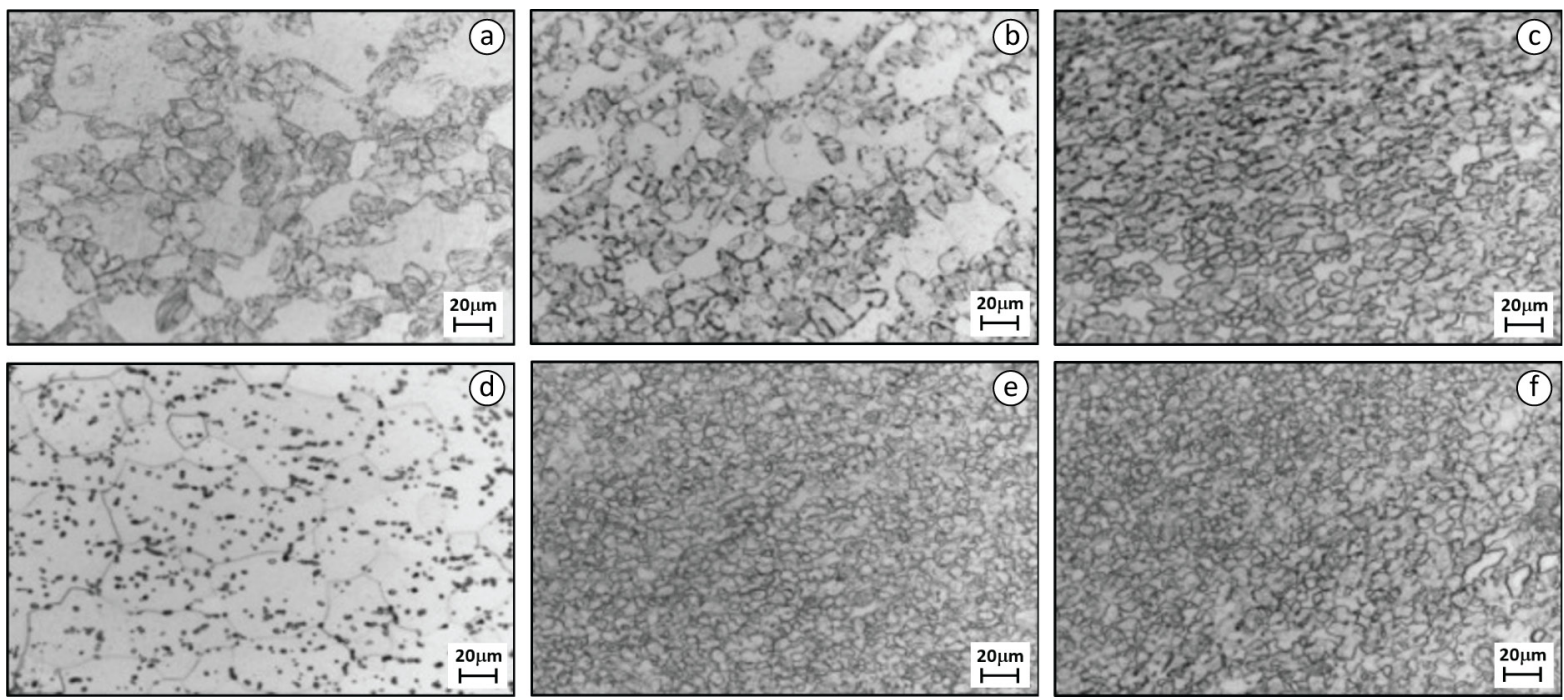

Figura 4. Microestrutura das principais regiões da solda dissimilar no lado do aço inoxidável ferrítico AISI 410S. (a) Zona de mistura superior próximo à interface (ZM-S); (b) Zona de mistura superior distante da interface (ZM-S); (c) ZTMA superior; (d) ZAC na região superior; (e) Zona de mistura inferior próximo à interface (ZM-I); (f) ZTMA na região inferior da solda.

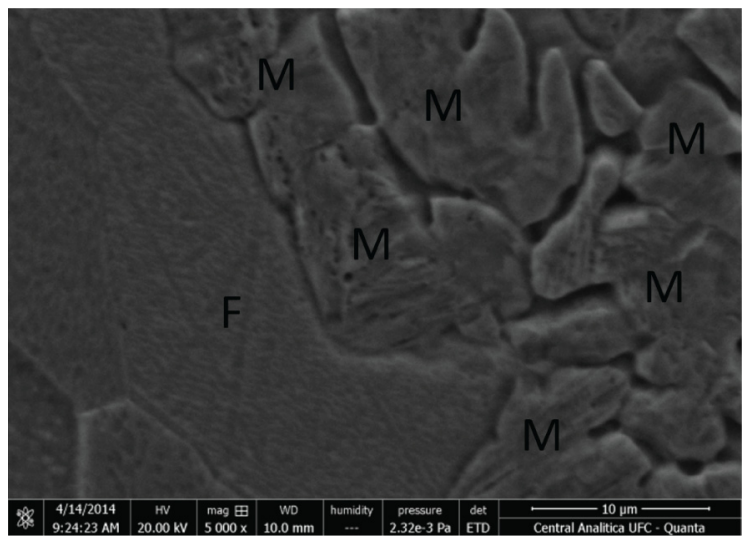

Figura 5. Micrografia obtida por MEV operando no modo SE com alta magnificação confirmando a presença de martensita (M) e de ferrita (F) na zona de mistura.

em martensita no resfriamento subsequente. Tal zona foi denominada de "zona de mistura superior" (ZM-S), a qual teve influência direta do contato com o ombro da ferramenta. Assim, a formação da ZM-S foi atribuída à maior quantidade de calor produzida na parte superior da junta.

Os aspectos microestruturais desta região podem estar associados à temperatura de pico alcançada nesta região. De acordo com os resultados de Darvazi and Iranmanesh [20] para a simulação térmica do aço inoxidável austenítico AISI $304 \mathrm{~L}$ com espessura de $3,2 \mathrm{~mm}$, existe um gradiente de temperatura entre a região do topo e do fundo da junta soldada, como pode ser observado na Figura 6. Tal resultado é suportado por outros estudos [21]. Comportamento semelhante também tem sido encontrado para aços inoxidáveis ferríticos [22].

No trabalho de Lakshminarayanan and Balasubramanian [23], foi reportado uma microestrutura semelhante para a região do topo da solda do aço inoxidável ferrítico AISI 409M constituída por ferrita e martensita. Contudo, a granulometria observada foi considerada refinada. Os autores consideraram que o refino de grão neste caso foi ocasionado pela grande deformação plástica causada pelo ombro da ferramenta. Esta deformação plástica juntamente com a alta temperatura experimentada é responsável pelo fenômeno de recristalização dinâmica do qual resulta a formação de grãos finos e equiaxiais [24,25]. 


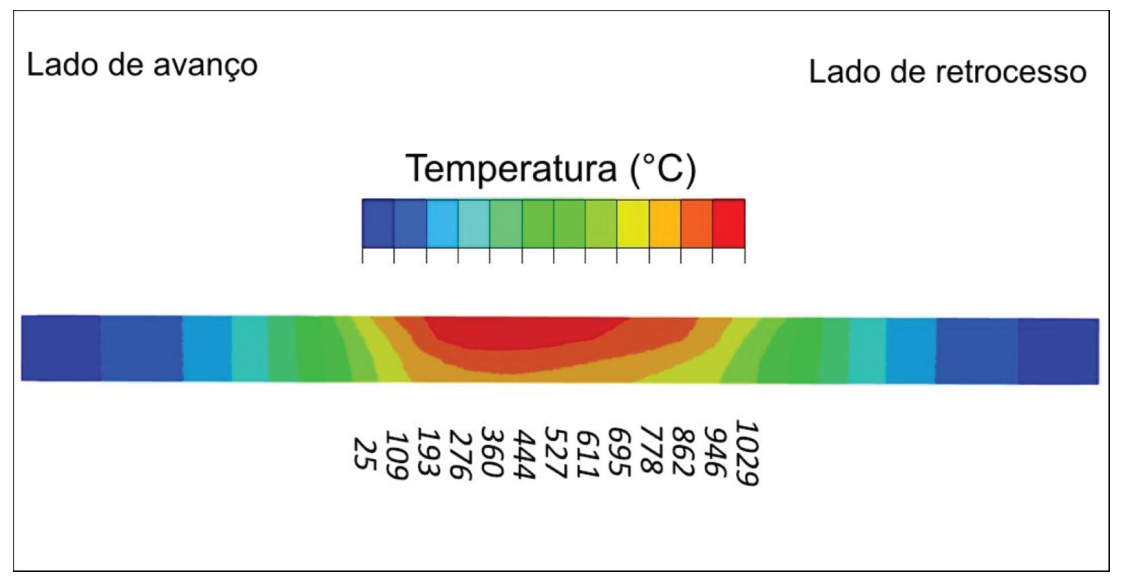

Figura 6. Distribuição de temperatura na seção transversal da solda FSW do aço inoxidável austenítico AISI 304L [20].

A segunda região corresponde à porção inferior da ZM, na qual foi observada uma microestrutura bastante refinada formada predominantemente por grãos pequenos de martensita. Esta zona foi denominada de "zona de mistura inferior" (ZM-I) e está indicada na Figura 3. Esta zona tem influência direta da deformação e aquecimento produzido pelo pino da ferramenta. As Figuras 4 e e $4 \mathrm{f}$ apresentam exemplos de micrografias obtidas por microscopia ótica desta zona. Buscando comparar de forma apropriada o refino de grão produzido nesta zona, estão postas lado a lado na Figura 7 duas micrografias tomadas em mesma magnificação, sendo a primeira correspondente à ZM-S e a segunda da ZM-I, além da microestrutura do metal de base (AISI 410S).
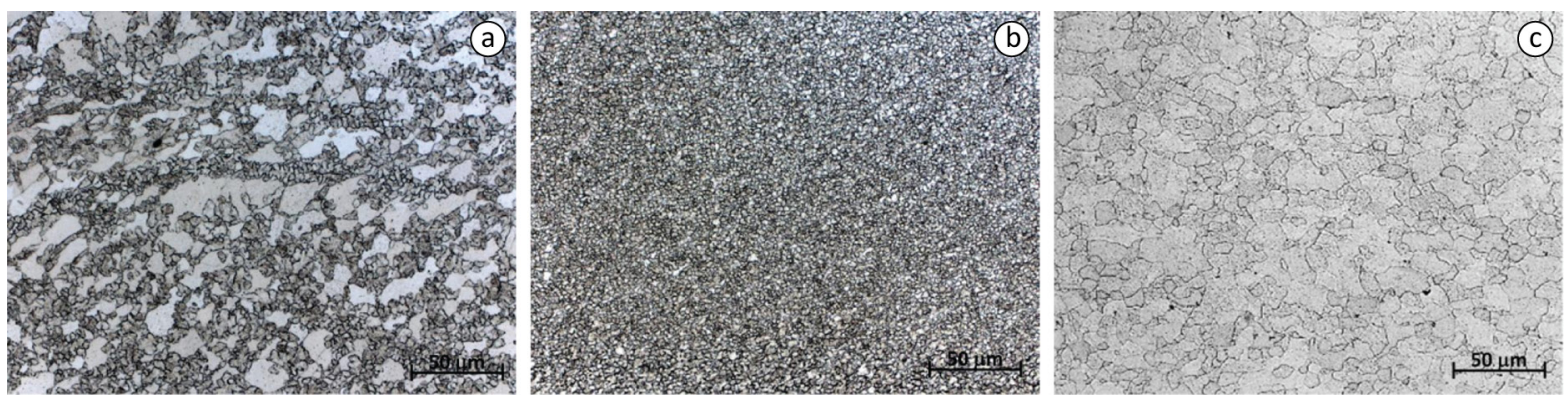

Figura 7. Microestrutura da zona de mistura do lado ferrítico (Aço AISI 410S) obtida por microscopia ótica. (a) ZM-S; (b) ZM-I; (c) MB; Aumento: 200X.

É possível comprovar por esta imagem o diminuto tamanho dos grãos na ZM-I. Alguns pontos podem ser elencados para discutir a formação desta zona. $O$ primeiro pode estar relacionado à menor quantidade de calor e consequente menor temperatura de pico alcançada. Além disso, o escoamento plástico produzido na região do pino da ferramenta proporciona uma recristalização dinâmica contínua desta zona, refinando consideravelmente os grãos. E por fim, esta recristalização dinâmica somada às transformações de fases de ferrita em austenita, resultando em martensita em condições de rápido resfriamento, conduzem a diminuição do tamanho dos grãos de ferrita pela substituição parcial desta fase por martensita.

Vale ressaltar que para a junta soldada por FSW, tanto a ZM-S quanto a ZM-I apresentaram tamanho dos grãos consideravelmente menores quando comparado àqueles produzidos na "zona fundida" e na "zona afetada pelo calor" de soldas produzidas por processos de fusão para o mesmo aço [26,27], indicando um forte potencial para o refinamento dos grãos para aços inoxidáveis ferríticos por esta técnica.

Para a região do topo da junta do lado ferrítico (AISI 410S) também foram avaliadas a microestrutura da ZTMA e da ZAC. As imagens de microscopia eletrônica de varredura da obtidas no modo SE da ZTMA mostram claramente a presença de grãos de ferrita em maior dimensão se comparado aos grãos de martensita, seguindo uma 
Microestrutura de uma Solda Dissimilar entre o Aço Inoxidável Ferrítico AISI 410S e o Aço Inoxidável Austenítico AISI 304L Soldado pelo Processo FSW

orientação específica, a qual é determinada pelo escoamento plástico do material durante a soldagem (Figura 8a). Uma análise detalhada da ZAC utilizando MEV revelou uma microestrutura mais refinada, com a estrutura ferrítica que corresponde a matriz em dimensão inferior ou praticamente proporcional aos grãos de martensita que as circundam, como pode ser observado na Figura $8 \mathrm{~b}$.
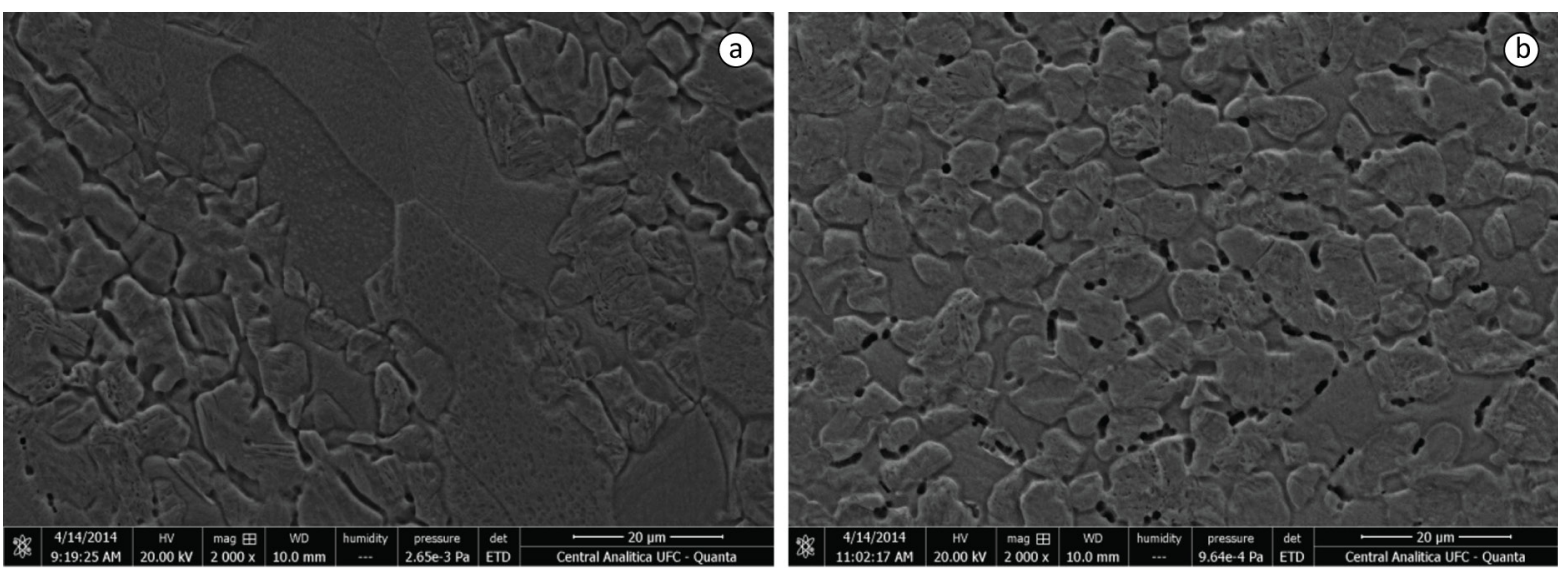

Figura 8. Imagens de microscopia eletrônica de varredura no modo SE da região do topo da junta dissimilar para o lado do aço inoxidável ferrítico AISI 410S. (a) Zona de mistura; (b) Zona afetada pelo calor.

É mostrado ainda que em certas regiões da solda foram observadas cavidades na interface ferrita/martensita após o ataque químico, as quais correspondem a valas devido a uma provável precipitação de carbonetos de cromo, provavelmente $\mathrm{Cr}_{23} \mathrm{C}_{6}$. A precipitação ocorreu, a princípio, nos contornos de grão da austenita prévia em alta temperatura. Embora a liga em estudo apresente uma concentração de carbono baixa, a redução dos teores de carbono abaixo de $0,03 \%$ não previne a sensitização, visto que a precipitação de carbonetos de cromo pode ocorrer rapidamente quando estes aços se encontram dentro da faixa temperatura para precipitação [28]. Van Niekerk e colaboradores [29] verificaram a ocorrência de sensitização em um aço inoxidável ferrítico contendo $12 \% \mathrm{Cr}$, mesmo com uma concentração de carbono de $0,011 \%$, dependendo da energia de soldagem aplicada. Matthews et al. [30] reportam que para menores velocidades de resfriamento a transformação martensítica é precedida de uma precipitação de carbonetos nos contornos de grão da austenita em alta temperatura. Outros autores também reportam a precipitação de carbonetos na soldagem de aços bifásicos ferrítico-martensíticos [31,32]. Vale ressaltar que embora tenha sido observada tal precipitação, esta não ocorreu em toda a região da solda, sendo observada somente em pontos específicos. Destaca-se ainda que o grau de precipitação foi bem pequeno, classificado como uma estrutura levemente dual e aceitável sob o ponto de vista de operação.

A Figura 9 apresenta o detalhe da micrografia para as diversas zonas da solda dissimilar, adquiridas no lado do aço inoxidável austenítico (304L). Neste grupo de imagens as Figuras 9a-9c são todos da parte superior da junta, referentes à: (ZM-S) zona de mistura superior próximo à interface (a), (ZTMA-S) zona termomecanicamente afetada superior (b) e (MB-S) metal de base superior. Nestas imagens verificam-se os contornos de grão da austenita, bandas escuras que correspondem à ferrita $\delta$, e pontos pretos que podem ser ainda algum precipitado de carbonetos $\mathrm{Cr}_{23} \mathrm{C}_{6}$ nos contornos de grão. Tanto no metal de base quanto na região da solda é possível observar a presença das bandas de ferrita $\delta$, em concentrações aparentemente similares. Observando o tamanho dos grãos, aparentemente também não foram observadas alterações significativas em termos de granulometria para o aço austenítico.

Analisando a microestrutura, verificou-se uma alteração na orientação das bandas de ferrita e uma característica serrilhada nos contornos da ZM devido à intensa deformação plástica. Contudo, a geometria dos grãos de austenita permaneceu de uma forma geral poligonal. Comparando a morfologia dos contornos de grão da zona de mistura com a do metal de base, verifica-se que os grãos também são poligonais, no entanto os seus contornos são retilíneos. Além disso, as bandas de ferrita $\delta$ seguem a orientação de laminação da chapa. A mesma análise foi executada para a porção inferior da junta, as quais são apresentadas na Figuras 9d-9f. Da mesma forma que na análise do topo, não foram observadas alterações significativas em termos de microestrutura e tamanho de grão. 

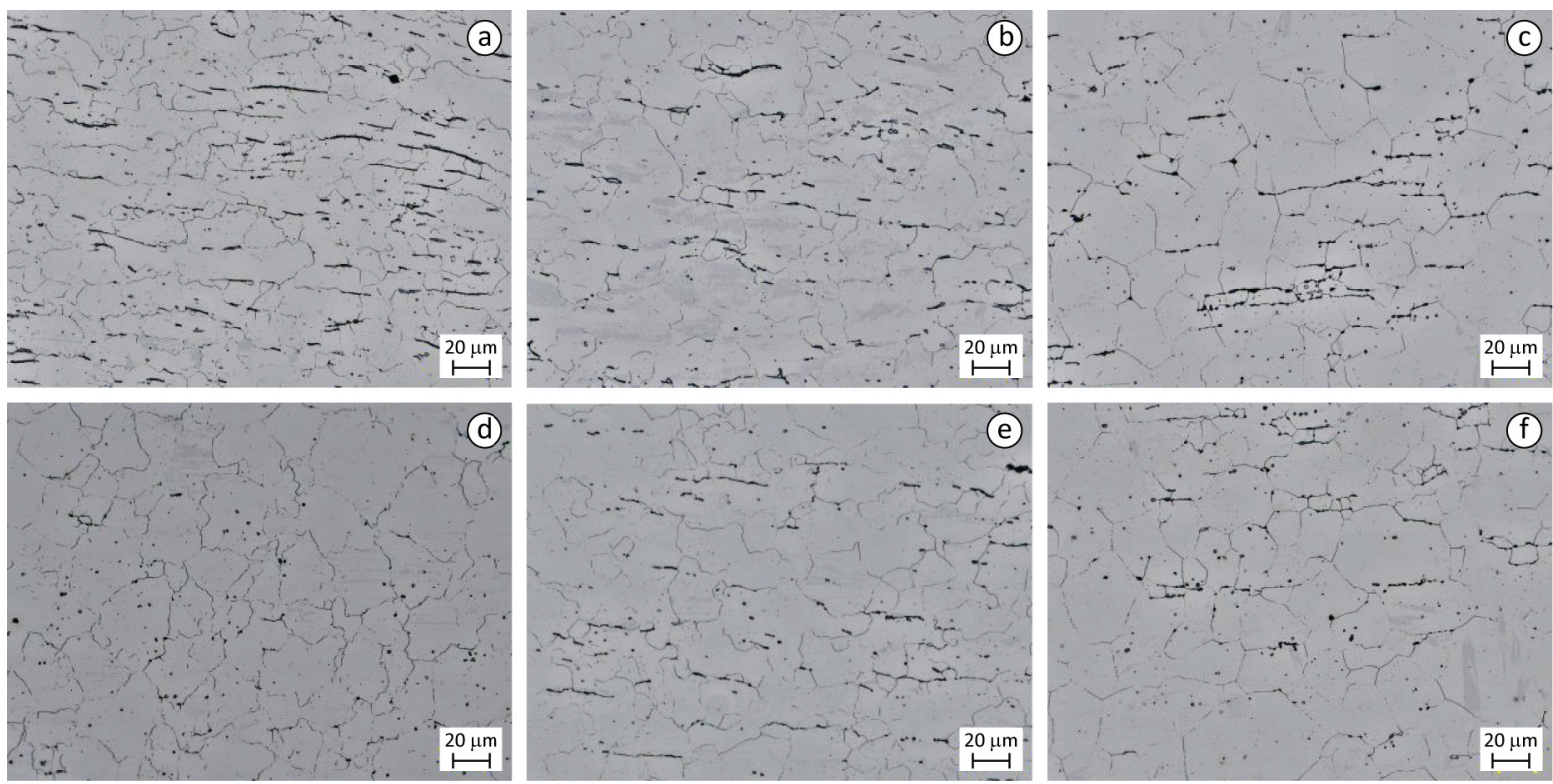

Figura 9. Microestrutura do aço AISI 304L obtida por microscopia ótica. (a) Zona de mistura superior (ZM-S); (b) zona termomecanicamente afetada superior (ZTMA-S); (c) Metal base superior (MB-S); (d) Zona de mistura na porção inferior (ZM-I); (e) zona termomecanicamente afetada na porção inferior (ZTMA-I); (f) Metal base inferior (MB-I). Aumento: 500X.

De fato, o crescimento do grão ferrítico para o aço AISI 410S normalmente ocorre efetivamente quando o material está em alta temperatura (superior a $1.200^{\circ} \mathrm{C}$ ), ou seja, o material estará no campo monofásico ferrítico. A Figura 10 apresenta o diagrama de fases em equilíbrio para a composição do metal de base do aço AISI $410 S$ calculado pelo programa Thermo-Calc ${ }^{\circledR}$ com base no princípio da mínima energia livre de Gibbs. Neste diagrama (Figura 10) o eixo horizontal corresponde à temperatura e o eixo vertical denota a fração molar das fases formadas (NPM), especialmente em termos de fração de ferrita (ccc) e austenita (cfc). Embora as transformações de fases decorrentes dos ciclos de aquecimento e resfriamento em soldagem ocorram fora das condições de equilíbrio, e isso possa resultar em alterações nas temperaturas efetivas em que estas transformações ocorrem e na própria transformação, podendo inclusive suprimir parcialmente ou por completo alguma transformação. Ainda assim, este diagrama é bastante útil, ajudando a compreender as prováveis alterações nas estruturas com base numa abordagem considerando condições de equilíbrio termodinâmico.

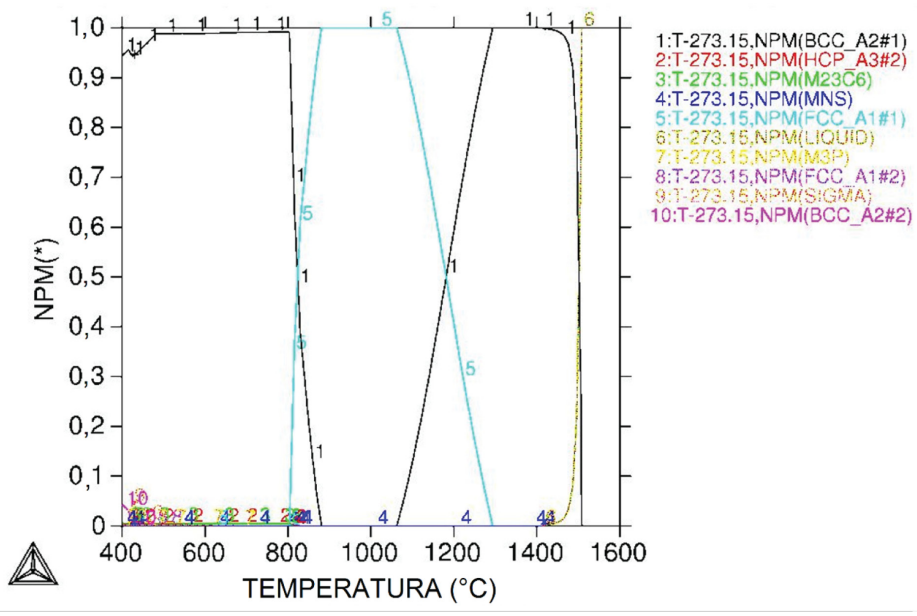

Figura 10. Diagrama de fase no equilíbrio para o aço inoxidável ferrítico AISI 410 S simulado utilizando o programa Thermo-Calc ${ }^{\circledR}$. NPM - fração molar das fases. 
Microestrutura de uma Solda Dissimilar entre o Aço Inoxidável Ferrítico AISI 410 e o Aço Inoxidável Austenítico AISI 304L Soldado pelo Processo FSW

Avaliando o diagrama é possível verificar que no aquecimento, a partir de $808^{\circ} \mathrm{C}$ o material começa a nuclear austenita, até que em $881^{\circ} \mathrm{C}$ o material torna-se completamente austenita. O material se mantem completamente austenítico até alcançar a temperatura de $1062^{\circ} \mathrm{C}$, acima da qual ocorre a reversão da austenita novamente para ferrita, completando esta transformação em $1293^{\circ} \mathrm{C}$. Assim, temos duas faixas de temperaturas em que o aço AISI $410 \mathrm{~S}$ é constituído por duas fases correspondendo à ferrita e austenita: $808^{\circ} \mathrm{C}$ a $881^{\circ} \mathrm{C}$ e entre $1062^{\circ} \mathrm{C}$ a $1293^{\circ} \mathrm{C}$; e uma na qual o material se transforma completamente de ferrita em austenita que corresponde ao campo entre $881^{\circ} \mathrm{C}$ a $1062^{\circ} \mathrm{C}$. Da temperatura ambiente até $808^{\circ} \mathrm{C}$ e acima de $1293^{\circ} \mathrm{C}$ o material é completamente ferrítico.

Em geral, o crescimento do grão ferrítico ocorre acima de $600^{\circ} \mathrm{C}$, porém a velocidade é tão rápida quanto maior for a temperatura. Aliado a isso, tem-se que o crescimento intenso ocorre especialmente quando o material se encontra em alta temperatura e completamente ferrítico, com isso, seria necessário que a ZM alcançasse temperaturas superiores à $1293^{\circ} \mathrm{C}$, conforme diagrama. Visto que no processo FSW as temperaturas alcançam valores da ordem de $80 \%$ da temperatura de fusão, é provável que o pico de máxima temperatura correspondesse ao campo bifásico austenita-ferrita do diagrama. Para esta discussão, é importante destacar que os grãos de austenita formados durante o aquecimento encontram-se num estado metaestável, e no resfriamento rápido devido ao ciclo térmico de soldagem, sofrerão transformação martensítica, dando origem aos grãos de martensita, como os vistos nas micrografias.

A transformação de fase no estado sólido de ferrita em austenita e de austenita em ferrita acarreta em processos de nucleação de crescimento de novos grãos. Isto implica necessariamente em refino de grãos, desde que não sejam alcançadas condições termodinâmicas para o crescimento exagerado dos novos grãos. Assim, pode-se atribuir em parte o refino de grão observado na zona de mistura do aço inoxidável ferrítico AISI 410 à estas transformações.

Yano et al. [33] estudando a soldagem FSW para um aço inoxidável ferrítico-martensítico contendo $11 \% \mathrm{Cr}$ encontraram que as estruturas com grãos uniformemente equiaxiais foram alcançadas com rotação da ferramenta de 100 rpm. Contudo, os autores não reportam se esta microestrutura foi observada ao longo de toda a zona de mistura. Os autores ressaltam ainda que com o aumento gradual de rotação da ferramenta até $300 \mathrm{rpm}$, foi observado um aumento na fração de martensita e maiores tamanhos de grão. Isto está associado ao aumento da quantidade de calor produzida com o aumento deste parâmetro.

No presente trabalho, conforme já destacado, houve uma região mais próxima da superfície (ZM-S) em que se observou uma maior fração de ferrita meio aos grãos de martensita. Neste, caso, se comparado ao metal de base, praticamente não houve aumento do tamanho dos grãos. É provável que a maior velocidade de rotação da ferramenta $(450 \mathrm{rpm})$ usada neste trabalho tenha sido alta o suficiente para proporcionar um aumento na quantidade de calor e, consequentemente, a manutenção do tamanho do grão ferrítico em alta temperatura, especialmente na região superior da zona de mistura (ZM-S), cujas temperaturas de pico são maiores e a velocidade de resfriamento é mais lenta. Por outro lado, tais regiões não foram acompanhadas por um processo intenso de refino grãos por transformação da ferrita em austenita, ao ponto de alcançar uma granulação tão refinada quanto a observada na ZM-I. Este comportamento pode estar associado à menor densidade de contornos de grãos para nucleação de grãos de austenita e à menor taxa de nucleação, dificultando o consumo do grão ferrítico pela austenita em alta temperatura.

Já para a porção inferior, cujo aquecimento é menos intenso e depende somente do atrito com o pino da ferramenta, observou-se uma microestrutura extremamente refinada. Isto pode ser o resultado de um menor aporte térmico, o que possibilitou um maior efeito da recristalização dinâmica e a uma densidade de contornos de grãos suficiente para a promoção de uma maior taxa de nucleação de novos grãos de austenita e subsequente transformação destes grãos em martensita.

Contudo, o mesmo não se aplica ao aço inoxidável austenítico AISI 304L, visto que o mesmo é praticamente monofásico da faixa de temperatura alcançada durante a soldagem. Ainda assim, um segundo mecanismo de refino de grão associado à recristalização é bem estabelecido na literatura para explicar o refino de grão na soldagem FSW.

De acordo com Lakshminarayanan and Balasubramanian [23] o processo de refinamento de grão na soldagem por FSW pode ser explicado de forma simples com base no escoamento plástico e recristalização dinâmica. Vários estudos têm demonstrado que o fenômeno da recristalização dinâmica, causado pelo aquecimento devido a fricção da ferramenta contra a peça, é o responsável pela geração de grãos finos e equiaxiais [23,24,34]. 
Com base na teoria da nucleação em recristalização dinâmica, materiais submetidos a condições de deformação a quente como na soldagem FSW, sofrem nucleação preferencialmente nos contornos de grão por um mecanismo denominado de formação de colares sucessivos, no qual pequenos grãos são nucleados em etapas que avançam do contorno de grão para o interior do grão original [35,36]. O processo de recristalização dinâmica ocorre por meio de dois diferentes processos em função de cada material: A recristalização dinâmica contínua, na qual novos grãos são desenvolvidos gradualmente pelo aumento da desorientação entre os sub-grãos. Já a recristalização dinâmica descontínua, os novos grãos são produzidos por nucleação e crescimento por meio da migração de contornos de grão de alto ângulo [36,37].

Assim, a diferença de refinamento dos grãos entre o aço inoxidável austenítico AISI 304L e o aço inoxidável ferrítico AISI 410 Sode estar associado, em parte, ao mecanismo de recristalização dinâmica associado à cada microestrutura, as quais estão associadas às diferenças de energia de falha de empilhamento entre estruturas ferríticas e austeníticas $[24,33,38,39]$. Materiais com baixa energia de falha de empilhamento apresentam maiores distancias entre discordâncias parciais, cuja recombinação por escorregamento com desvio (cross-slip) e por escalada (climb) em um plano de escorregamento é difícil e requer grande quantidade de energia, o que dificulta a reorganização de áreas defeituosas. Já materiais com maiores energias de falha de empilhamento possuem menor efeito de repulsão entre as discordâncias parciais, tornando-as mais próximas e facilitando a sua recombinação em planos de escorregamento, facilitando assim a reorganização da região distorcida do cristal [23,36,40].

Padilha [41] destaca que materiais com baixa energia de falha de empilhamento produzem maior densidade de discordâncias, maior uniformidade na distribuição dentro do volume do cristal, maior energia de deformação armazenada. Este comportamento implica em maior capacidade de encruamento, maior resistência à fluência e maior susceptibilidade à corrosão sob-tensão.

Logo, aços inoxidáveis austeníticos os quais possuem baixa energia de falha de empilhamento estão sujeitos ao mecanismo de recristalização dinâmica descontínua. Em contrapartida, os aços inoxidáveis ferríticos, cuja energia de falha de empilhamento é alta, a recristalização dinâmica ocorre de forma contínua, favorecendo significativamente o refino dos grãos e resultando em microestruturas notadamente refinadas.

\section{Conclusões}

Com base nos resultados apresentados neste estudo referente ao refino de grão na soldagem dissimilar entre os aços inoxidáveis AISI 410S e AISI 304L pelo processo friction stir welding foi possível concluir que:

- A microestrutura do aço inoxidável AISI $410 S$, inicialmente ferrítica sofreu uma intensa austenitização e subsequente transformação martensítica no resfriamento, resultando em uma mistura de martensita e ferrita na zona de mistura (ZM), zona termomecanicamente afetada (ZTMA) e zona afetada pelo calor (ZAC).

- As características do processo de soldagem FSW para o aço inoxidável ferrítico AISI 410S resultaram num refino de grão na zona de mistura (ZM), zona termomecanicamente afetada (ZTMA), especialmente na região inferior da solda.

- Para o aço inoxidável austenítico AISI 304L não foram observadas alterações microestruturais relevantes, nem refino de grão evidente, permanecendo o tamanho do grão nas zonas das soldas aproximadamente o mesmo do metal de base.

- Foi observado um gradiente de refino de grão para o aço inoxidável ferrítico AISI 410S, sendo o refino mais intenso observado na porção inferior da junta, na zona de mistura.

- A diferença de refino de grão entre os aços inoxidáveis ferríticos e austeníticos foi atribuído às diferenças de energia de falha de empilhamento entre as estruturas de ambos os aços, afetando o fenômeno de recristalização dinâmica.

- Outro fator que teve influência sobre a granulometria final da solda no lado do aço inoxidável ferrítico AISI 410 S foi o fato da liga sofrer transformação de fase no estado sólido, o que acarreta no surgimento de novos grãos e, consequentemente, num refinamento da estrutura. 
Microestrutura de uma Solda Dissimilar entre o Aço Inoxidável Ferrítico AISI 410S e o Aço Inoxidável Austenítico AISI 304L Soldado pelo Processo FSW

\section{Agradecimentos}

Os autores gostariam de agradecer ao Laboratório de Engenharia de Soldagem da Universidade Federal do Ceará e ao Solid State Joining Process / Helmholtz-Zentrum Geesthacht (Alemanha) pela infraestrutura para a realização do trabalho. Ao CNPq pelo financiamento da pesquisa e concessão de bolsas. À FUNCAP/CAPES pelo incentivo à cooperação internacional. Os Autores agradecem a Central Analítica-UFC/CT-INFRA/MCTI-SISNANO/ Pró-Equipamentos CAPES.

\section{Referências}

[1] Smith WF. Structure and properties of engineering alloys. New York: McGraw-Hill; 1993.

[2] Lippold JC, Kotecki DJ. Welding metallurgy and weldability of stainless steels. New Jersey: John Wiley \& Sons; 2005.

[3] Lai JKL, Lo KH, Shek CH. Stainless steel an introduction and their recent developments. 1st ed. Brussels: Bentham Books; 2012.

[4] Antunes PD, Correa EO, Barbosa RP, Silva EM, Padilha AF, Guimarães $P M$. Effect of weld metal chemistry on stress corrosion cracking behavior of AISI 444 ferritic stainless steel weldments in boiling chloride solution. Materials and Corrosion. 2013;64(5):415-421. http://dx.doi.org/10.1002/maco.201106186.

[5] Silva CC, Farias JP, Miranda HC, Guimarães RF, Menezes JWA, Marcelino MA No. Microstructural characterization of the HAZ in AISI 444 ferritic stainless steel welds. Materials Characterization. 2008;59(5):528-533. http://dx.doi.org/10.1016/j. matchar.2007.03.011.

[6] Kou S, Le Y. Welding parameters and the grain structure of weld metal: a thermodynamic consideration. Metallurgical and Materials Transactions A: Physical Metallurgy and Materials Science. 1988;19(4):1075-1082. http://dx.doi.org/10.1007/ BF02628392.

[7] Greeff ML, Du Toit M. Looking at the sensitization of $11-12 \%$ chromium EN 1.4003 stainless steels during welding. Welding Journal. 2006;85(11):243-251.

[8] Lakshminarayanan AK, Balasubramanian V, Reddy GM. Microstructure and mechanical properties of electron beamwelded AISI 409M-grade ferritic stainless steel. International Journal of Advanced Manufacturing Technology. 2011;55(14):153-162. http://dx.doi.org/10.1007/s00170-010-3044-1.

[9] Lakshminarayanan AK, Balasubramanian V. Characteristics of laser beam and friction stir welded AISI 409M ferritic stainless steel joints. Journal of Materials Engineering and Performance. 2012;21(4):530-539. http://dx.doi.org/10.1007/s11665-0119943-y.

[10] Rajasekhar A, Reddy GM, Mohandas T, Murti VSR. Influence of austenitizing temperature on microstructure and mechanical properties of AISI 431 martensitic stainless steel electron beam welds. Materials \& Design. 2009;30(5):1612-1624. http://dx.doi. org/10.1016/j.matdes.2008.07.042.

[11] Reddy GM, Mohandas T. Explorative studies on grain refinement of ferritic stainless steel welds. Journal of Materials Science Letters. 2001;20(8):721-723. http://dx.doi.org/10.1023/A:1010963025259.

[12] Villafuerte JC, Pardo E, Kerr HW. The effect of alloy composition and welding conditions on columnar-equiaxed transitions in ferritic stainless steel gas-tungsten arc welds. Metallurgical Transactions A: Physical Metallurgy and Materials Science. 1990;21(7):2009-2019. http://dx.doi.org/10.1007/BF02647249.

[13] Thomas WM, Nicholas ED, Needham JC, Murch MG, TempleSmith P, Dawes CJ. Friction Stir Butt Welding. UK International Patent Application No. PCT/GB92/02203 and GB Patent Appl. No. 9125978.9. 1991. Dec 6.
[14] Coelho RS, Kostka A, dos Santos JF, Pyzalla AR. EBSD technique visualization of material flow in aluminum to steel friction-stir dissimilar welding. Advanced Engineering Materials. 2008;10(12):11271133. http://dx.doi.org/10.1002/adem.200800227.

[15] Mishra RS, Ma ZY. Friction stir welding and processing. Materials Science and Engineering R Reports. 2005;50(1-2):1-78. http:// dx.doi.org/10.1016/j.mser.2005.07.001.

[16] Nandan R, Debroy T, Bhadeshia HKDH. Recent advances in friction-stir welding: process, weldment structure and properties. Progress in Materials Science. 2008;53(6):980-1023. http:// dx.doi.org/10.1016/j.pmatsci.2008.05.001.

[17] Hütsch LL, Hütsch J, Herzberg K, Santos JF, Huber N. Increased Room Temperature Formability of Mg AZ31 by High Speed Friction Stir Processing. Materials \& Design. 2014;54:980-988. http://dx.doi.org/10.1016/j.matdes.2013.08.108.

[18] Caetano GQ, Bergmann LA, Silva CC. Joining of similar ferritic and austenitic stainless steels by the "Friction Stir Welding" process. Hamburg: Helmholtz-Zentrum Geesthacht; 2013. Technical Report.

[19] Threadgill PL. Terminology in friction stir welding. Science and Technology of Welding and Joining. 2007;12(4):357-360. http:// dx.doi.org/10.1179/174329307X197629.

[20] Darvazi AR, Iranmanesh M. Thermal modeling of friction stir welding of stainless steel 304L. International Journal of Advanced Manufacturing Technology. 2014;75(9-12):1299-1307. http:// dx.doi.org/10.1007/s00170-014-6203-y.

[21] HeX, Gu F, Ball A. A review of numerical analysis of friction stir welding. Progress in Materials Science. 2014;65:1-66. http:// dx.doi.org/10.1016/j.pmatsci.2014.03.003.

[22] Cho H-H, Hong S-T, Roh J-H, Choi H-S, Kang SH, Steel RJ, et al. Three-dimensional numerical and experimental investigation on friction stir welding processes of ferritic stainless steel. Acta Materialia. 2013;61(7):2649-2661. http://dx.doi.org/10.1016/j. actamat.2013.01.045.

[23] Lakshminarayanan AK, Balasubramanian V. An assessment of microstructure, hardness, tensile and impact strength of friction stir welded ferritic stainless steel joints. Materials \& Design. 2010;31(10):4592-4600. http://dx.doi.org/10.1016/j. matdes.2010.05.049.

[24] Sato YS, Nelson TW, Sterling CJ. Recrystallization in type 304L stainless steel during friction stirring. Acta Materialia. 2005a;53(3):637645. http://dx.doi.org/10.1016/j.actamat.2004.10.017.

[25] Park SHC, Sato YS, Kokawa H, Okamoto K, Hirano S, Inagaki M. Microstructural characterisation of stir zone containing residual ferrite in friction stir welded 304 austenitic stainless steel. Science and Technology of Welding and Joining. 2005;10(5):550-556. http://dx.doi.org/10.1179/174329305X46691.

[26] Khorrami MS, Mostafaei MA, Pouraliakbar H, Kokabi AH. Study on microstructure and mechanical characteristics of low-carbon steel and ferritic stainless steel joints. Materials Science and Engineering A. 2014;608:35-45. http://dx.doi.org/10.1016/j. msea.2014.04.065. 
[27] Silva CC, Januário Costa AN, Sant'Ana HB, Farias JP. Alterações Microestruturais na ZAC do Aço Inoxidável AISI 410S - Efeitos Sobre a Resistência à Corrosão. Soldagem \& Inspeção. 2006;11:188-199.

[28] Folkhard E. Welding metallurgy of stainless steels. Vienna: Springer-Verlag; 1988.

[29] Van Niekerk CJ, Du Toit M, Erwee MW. Sensitization of AISI 409 ferritic stainless steel during low heat input arc welding. Welding in the World. 2012;56(5-6):54-64. http://dx.doi.org/10.1007/ BF03321350.

[30] Matthews LM, Griesel B, Longman PT, Van Rooyen GT, Prozzi JM Sensitization in low-carbon $12 \%$ chromium containing stainless steels. In: Proceedings of the 14th International Corrosion Congress; 1999; Cape Town, South Africa. Irene: Document Transformation Technologies; 1999. p. 332.

[31] Marshal, A.E., Farrar, J.C.M. Welding of ferritic and martensitic $11-14 \% \mathrm{Cr}$ steels. Melbourne: International Institute of Welding; 2000. p. 1-32. (IIW Document, IXH 494-2000).

[32] Frangini S, Mignone A. Modified electrochemical potentiokinetic reactivation method for detecting sensitization in $12 \% \mathrm{Cr}$ ferritic stainless steel. Corrosion. 1992;48(9):715-726. http://dx.doi. org/10.5006/1.3315992.

[33] Yano Y, Sato YS, Sekio Y, Ohtsuka S, Kaito T, Ogawa R, et al. Mechanical properties of friction stir welded $11 \mathrm{Cr}$-ferritic/ martensitic steel. Journal of Nuclear Materials. 2013;442(13):S524-S528. http://dx.doi.org/10.1016/j.jnucmat.2012.10.038.

[34] Sato YS, Nelson TW, Sterling CJ, Steel RJ, Pettersson C-O. Microstructure and mechanical properties of friction stir welded SAF 2507 super duplex stainless steel. Materials Science and Engineering A. 2005;397(1-2):376-384. http:// dx.doi.org/10.1016/j.msea.2005.02.054.

[35] Padilha AF, Siciliano FJr. Encruamento, recristalização, crescimento de grão e textura. 3rd ed. São Paulo: ABM; 2005. 232 p.

[36] Humphreys FJ, Hatherly M. Recrystallization and related annealing phenomena. 2nd ed. Oxford: Elsevier; 2004.

[37] Su J-Q, Nelson TW, Sterling CJ. Microstructure evolution during FSW/FSP of high strength aluminum alloys. Materials Science and Engineering A. 2005;405(1-2):277-286. http://dx.doi. org/10.1016/j.msea.2005.06.009.

[38] Reynolds AP, Tang W, Gnaupel-Herold T, Prask H. Structure, properties, and residual stress of $304 \mathrm{~L}$ stainless steel friction stir welds. Scripta Materialia. 2003;48(9):1289-1294. http:// dx.doi.org/10.1016/S1359-6462(03)00024-1.

[39] Cho H-H, Han HN, Hong S-T, Park J-H, Kwon Y-J, Kim S-H, et al. Microstructural analysis of friction stir welded ferritic stainless steel. Materials Science and Engineering A. 2011;528(6):28892894. http://dx.doi.org/10.1016/j.msea.2010.12.061.

[40] Schramm RE, Reed RP. Stacking fault energies of seven commercial austenitic stainless steels. Metallurgical and Materials Transactions A: Physical Metallurgy and Materials Science. 1975;6A(7):1345-1351. http://dx.doi.org/10.1007/ BF02641927.

[41] Padilha AF. Materiais de engenharia: microestrutura e propriedades. São Paulo: Hemus; 2000. 343 p. Edição Eletrônica. (v. 1). 